\title{
Pneumocephalus as a complication of esophageal carcinoma
}

\author{
Takahiro Shimizu • Yoshiaki Tokuyama • Kana Shimomura • Toshikazu Hirayama • \\ Tatsuhiro Arai • Takeharu Enomoto • Kazuhiro Miura • Takehito Otsubo • \\ Yasuhiro Hasegawa
}

Received: 26 May 2010 / Accepted: 29 June 2010 / Published online: 21 August 2010

(C) Springer-Verlag London Ltd 2010

A 73-year-old man presented with a loss of consciousness. He was comatose at the time of admission with a GCS of 5 and no localized neurological signs. Medical records indicated that the patient had undergone surgical treatment for esophageal carcinoma 2 years previously. Metastases developed in the reconstructed stomach tube and middle esophagus 6 months after surgery, and the patient had therefore received radiotherapy. Computed tomography (CT) of the head revealed gaseous distention in the subarachnoid space around the cortex. Some air was visible around the brain stem (Fig.1). No head injuries and no skull-base fracture were observed. The radiological diagnosis was a pneumocephalus. He died 2 days after admission.

T. Shimizu $(\bowtie) \cdot$ Y. Tokuyama $\cdot$ K. Shimomura $\cdot$ T. Hirayama $\cdot$

Y. Hasegawa

Department of Internal Medicine, Division of Neurology,

St. Marianna University School of Medicine,

2-16-1 Sugao, Miyamae-ku,

Kawasaki City, Kanagawa 216-8511, Japan

e-mail: shimi-taka@marianna-u.ac.jp

Y. Tokuyama

e-mail: hsmtoku555@yahoo.co.jp

K. Shimomura

e-mail: k2shimomura@marianna-u.ac.jp

T. Hirayama

e-mail: t2hira@marianna-u.ac.jp

Y. Hasegawa

e-mail: hasegawa-neurol1@marianna-u.ac.jp
Pneumocephalus is a rare disease that has most often been described as a result of skull base fracture or intracranial and spinal operations. A subarachnoid-pleural fistula and intracranial air may occur after lung resection [1]. Willheim reported pneumocephalus as a complication of metastases in sacral carcinoma [2]. This is a very rare eroding tumor that may cause pneumocephalus without either trauma or surgery. We think that the destruction of the esophagus and tissue of the esophageal carcinoma, which was hastened by eroding bone, caused a communication between the subarachnoid space and esophagus. The diagnosis was of pneumocephalus as a complication of esophageal carcinoma.

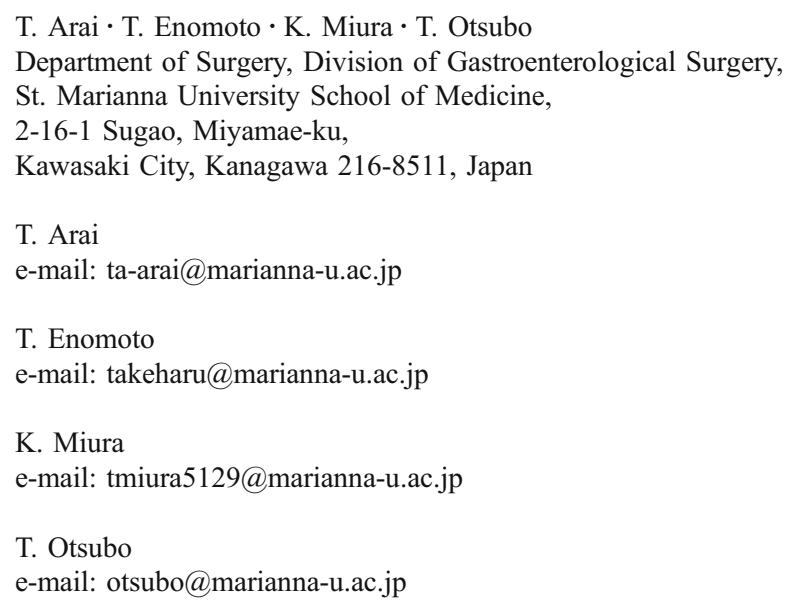


Fig. 1 Axial CT of the brain showing profound gaseous attenuation in the subarachnoid space, cortical sulci and ambient cistern

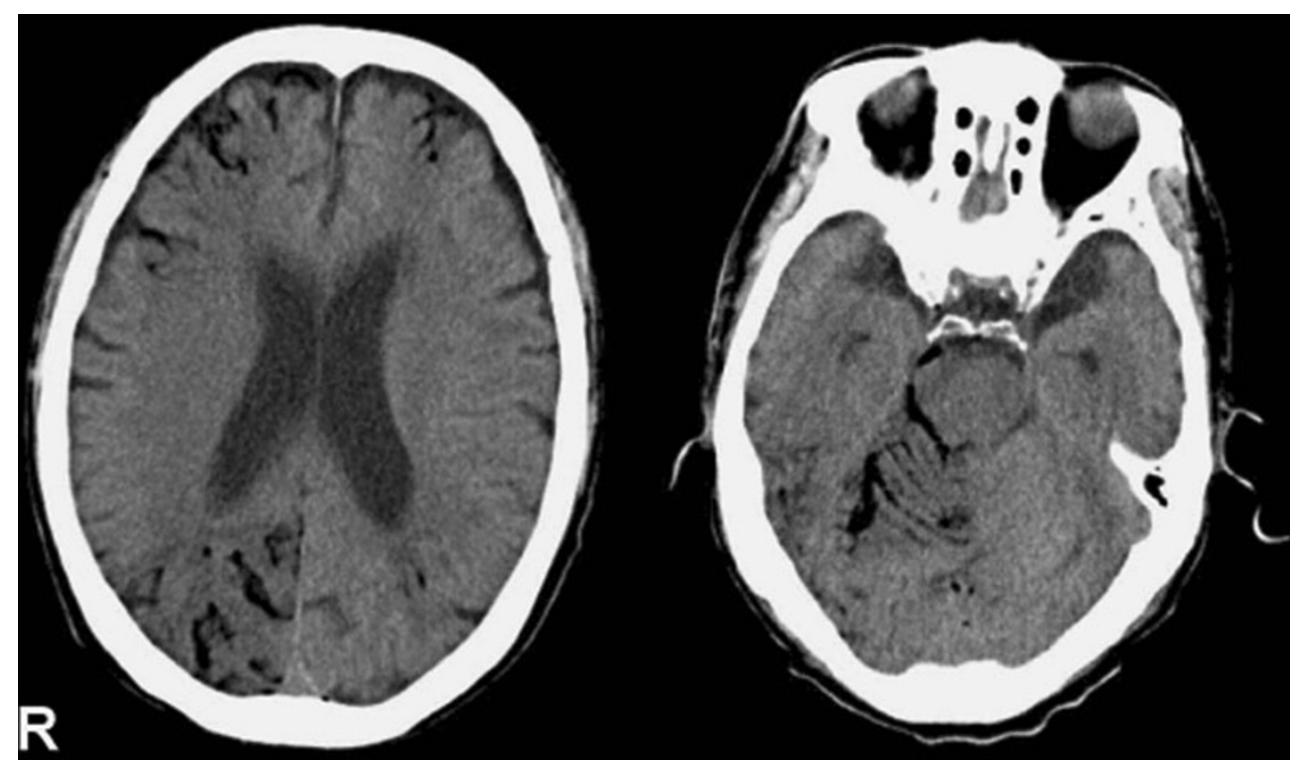

\section{Conflicts of interest None.}

\section{References}

1. Reddy HV, Queen S, Prakash D et al (2003) Tension Pneumocehalus: an unusual complication after lung resection. Eur J Cardiothorac Surg 24:171-173
2. Willheim K, Jurjevic A, Tomic Z (1998) Pneumocehalus as a complication of metastases and eroding infection in the sacral region. J Neurol Neurosurg Psychiatry 64:136-137 